\section{CAFTA-DR, importaciones de granos básicos y la destrucción de la agricultura salvadoreña}

Luis René Cáceres Araniva ${ }^{1}$

Palabras clave: producción agrícola, empleo, remesas, tarifa, emigración.

\section{Resumen}

Este trabajo presenta argumentos que defienden que no es conveniente para nuestro país poner en vigor la cláusula establecida en el tratado del CAFTA-DR sobre la importación de maíz y maicillo libres de impuestos. Se insiste en que la agricultura nacional, lo mismo que el sector manufacturero, ha sufrido severas contracciones desde los años noventa y una medida de esa naturaleza podría dar un golpe terminal al sector, con consecuencias en términos de aumentos de desempleo, violencia, inseguridad alimentaria y emigración regular. El trabajo presenta datos que permiten apreciar la contracción de los sectores productivos a raíz del crecimiento desmedido de las importaciones resultantes de la reducción de la tarifa a las importaciones, situación que se agravaría si la cláusula en cuestión entrara en vigor. La recomendación es que se negocie con los EE. UU. que esa cláusula se deje sin efecto. En los anexos, se presentan propuestas relacionadas con inversiones en el sector agropecuario, con el apoyo a la caficultura nacional mediante la emisión de una moneda electrónica y sobre el diseño de un portal electrónico para la venta de café en el mercado nacional e internacional.

\section{Introducción}

El tratado de libre comercio suscrito en agosto de 2005 entre el Gobierno de los EE. UU. y los Gobiernos de los países de Centroamérica y República Dominicana estableció que el maíz y el sorgo gozarán de entrada libre de impuestos a los países después de 15 años de firmado el tratado.

\footnotetext{
1 Economista salvadoreño.
} 
Establece, además, que el mismo trato recibirán otros productos agropecuarios, como leche, mantequilla, carne de res y de cerdo, en plazos de entre 17 y 20 años después de la suscripción. Esto indica que este año entrará en vigor la cláusula de libre importación de maíz y sorgo, y que en los años siguientes otros bienes gozarán del mismo tratamiento.

Esta sección argumenta que esa medida no es conveniente para la economía y la sociedad salvadoreña y centroamericana, y que, si se implementara, las consecuencias serían funestas. En siguientes secciones, se describe la situación de la economía salvadoreña en las últimas tres décadas y las repercusiones adversas sobre el empleo y el crecimiento económico derivadas de la extrema apertura económica, que hace ver lo inapropiado que serían las mayores importaciones de granos básicos. En tres anexos se presentan planteamientos para apoyar al sector agropecuario; el primero sobre la importancia de incrementar las inversiones en el sector, el segundo sobre la circulación de una moneda virtual que podría beneficiar al sector cafetalero y el tercero sobre un portal de exportación de café.

\section{Algunos datos}

Las exportaciones salvadoreñas hacia los EE. UU. no han tenido un dinamismo notable, como se muestra en el gráfico $1, y$ muestran tendencias al estancamiento desde 2013, por lo que no han conducido a incrementar la tasa de crecimiento de la economía salvadoreña. Esto se explica por el hecho de que las exportaciones salvadoreñas hacia ese país están constituidas principalmente por maquila, cuyo valor agregado a la industria nacional es bajo. En el caso de México, Velut (2011) ha reportado que el valor agregado generado por la industria de maquila es solo de $5 \%$ y que esto explica la tendencia al estancamiento de la economía mexicana, a pesar de que exporta a los EE. UU. montos considerables, de US\$370,000 millones en 2019. Aun así, se disputa con El Salvador el último lugar en el crecimiento económico de los países latinoamericanos. Las importaciones desde los EE. UU. muestran mayor dinamismo, pero han caído en los últimos años (gráfico 2).

Gráfico 1. Exportaciones de El Salvador hacia los EE. UU. (en millones de US\$, 2000-2019)

\section{ESEXPORTSUS}

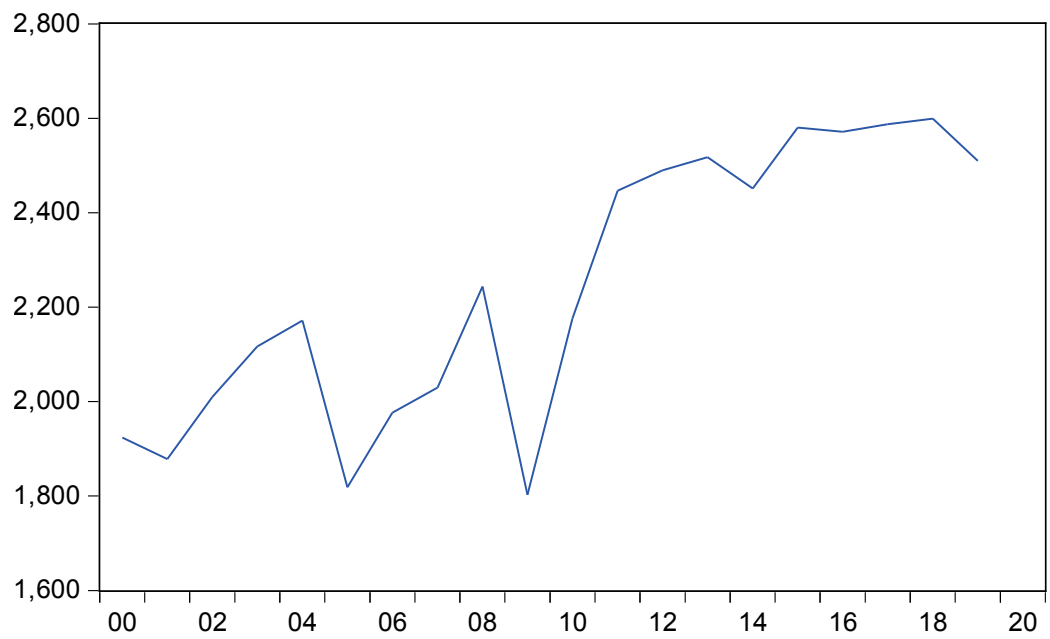


Gráfico 2. Importaciones de El Salvador desde los EE. UU. (en millones de US\$, 2000-2019)

\section{ESIMPORTSUS}

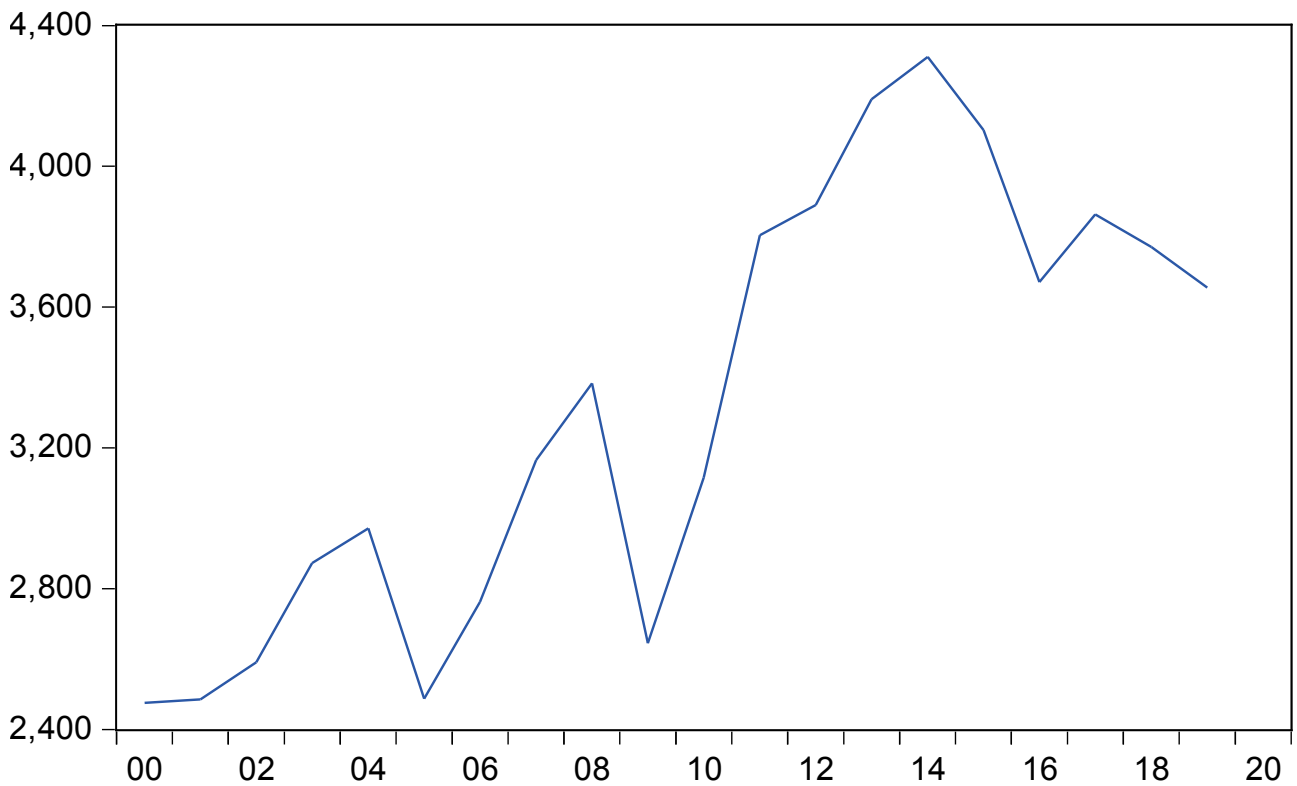

Hay que tomar en cuenta la experiencia de México, que en el marco del NAFTA eliminó las tarifas a la importación de maíz procedente de los EE. UU. Varios autores han señalado que esa medida condujo a incrementar el desempleo y la pobreza en las áreas rurales. Velut (2011) indica que 5.4 millones de familias perdieron sus empleos y tuvieron que emigrar a las ciudades, a los EE. UU. o entraron a actividades criminales. Este autor describe la situación en estos términos:

"The first victims of these tectonic shifts were subsistence farmers. The liberation of corn and other commodities is estimated to have reduced farm income for as many three million small producers...Given their low education levels, campesinos were ill-equipped to transfer to other sectors of the economy. Some of them managed to integrate the service sector, whose share of the economy has significantly increased under NAFTA - from 51\% in 1994 to $60 \%$ in 2006 . Others were forced to join the ranks of the informal sector, consisting mainly of self-employment and employment in microenterprises. Yet others opted for migrating to the United States. Throughout the 1990s, the number of Mexican immigrants crossing the US border increased from about 350,000 per year before NAFTA to half million in the early 2000, before declining significantly in the second half of the decade partly under the effect of the financial crisis... In words of one analyst, 'migration has become an alternative to development"' (p. 8).

Así mismo, después de la entrada en vigor del NAFTA, el empleo industrial en México ha decrecido de 17.7 millones en 1993 a 12.3 millones en 2016 (Floyd, 2018). 
No hay razón para pensar que una situación similar no ocurriría en El Salvador; al contrario, puede ser más grave dado el actual alto desempleo y la contracción económica ocasionados por la pandemia del COVID-19.

\section{Contracción del sector agropecuario}

La pandemia hace ver que no es el momento para liberalizar la importación de granos básicos, pero hay otras razones. Por una parte, el sector agropecuario enfrenta serios problemas derivados del cambio climático, la escasez de agua y la desertificación; hay que tomar en cuenta los estragos de huracanes que con frecuencia azotan a la región centroamericana, de manera que un golpe adicional procedente del CAFTA-DR podría terminar con el sector agropecuario. En el gráfico 3, se muestra la participación del valor agregado del sector agrícola en el producto interno bruto (PIB) de El Salvador y se observa que, desde principios de los años noventa, esta participación ha venido cayendo hasta representar solamente $4 \%$ del PIB en 2018, uno de los valores más bajos de América Latina.

Gráfico 3. Participación del sector agrícola en el PIB de El Salvador (1990-2018)

ESAGRICULTURA

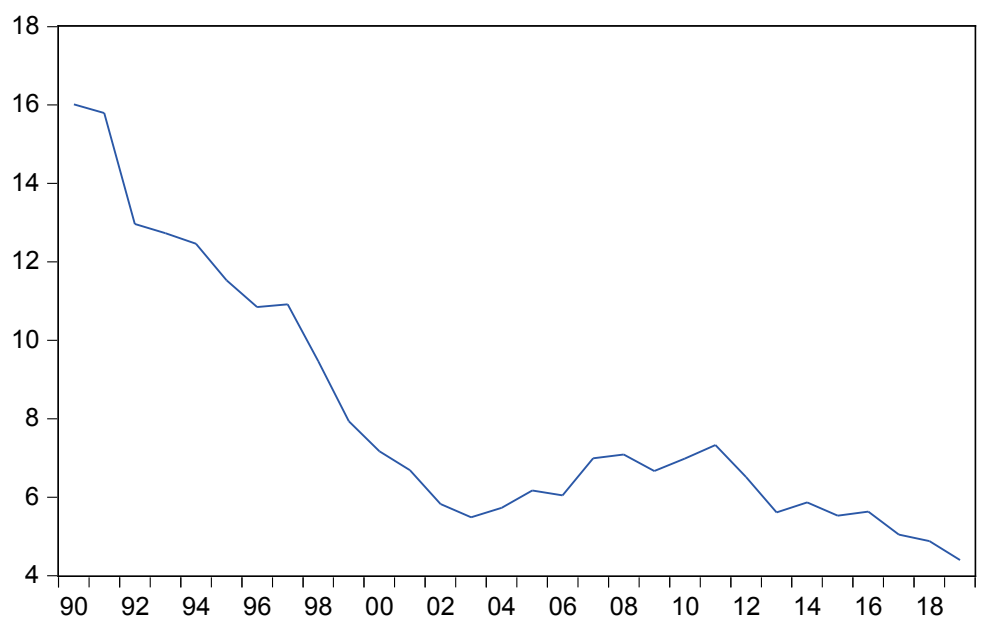

Para comparar, se presentan en el gráfico 4 las trayectorias de las participaciones del sector agrícola en el PIB de Guatemala, Honduras y Nicaragua, países donde la agricultura tiene una mayor representación en la economía; en 2018, en Nicaragua, representaba $16 \%$; en Honduras, $12 \%$, y en Guatemala, $10 \%$. 
Gráfico 4. Participación del sector agrícola en el PIB de Guatemala, Honduras y Nicaragua (1990-2018)

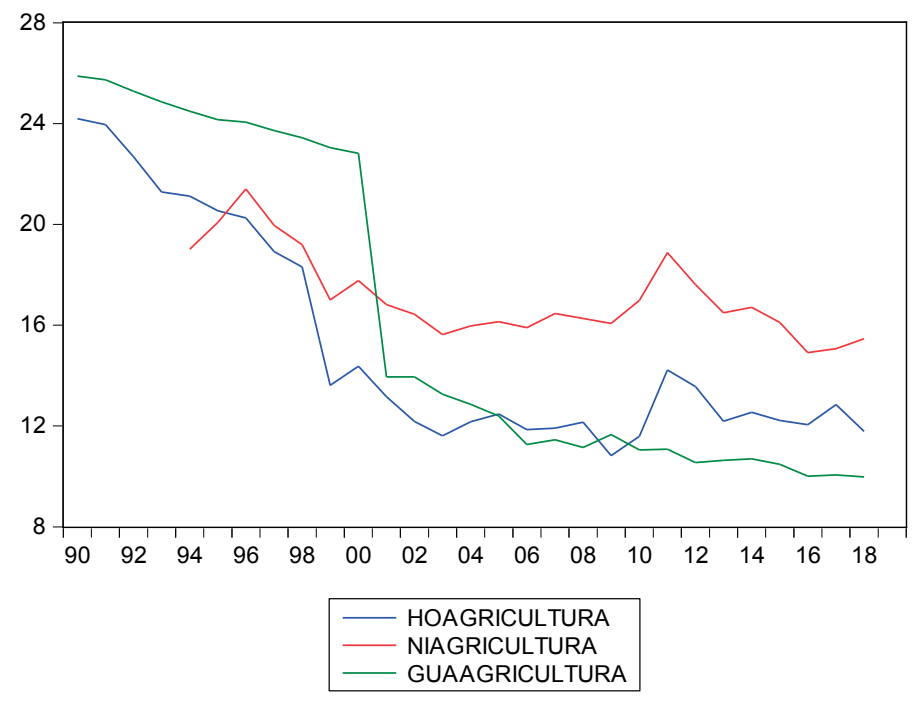

\section{Caídas del empleo}

La contracción del sector agrícola en El Salvador ha dado lugar a la pérdida de empleos; el gráfico 5 muestra que el empleo masculino en el sector, como porcentaje del total de empleo masculino, ha caído de manera pronunciada.

Gráfico 5. Tasas de empleo femenino y masculino en el sector agrícola

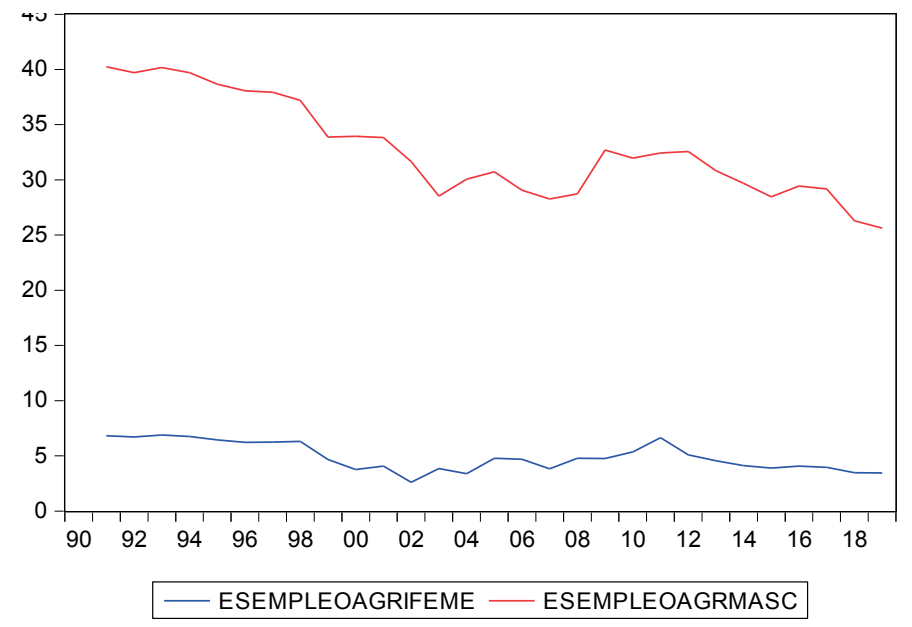


Una trayectoria similar muestra la participación del sector manufacturero en el PIB, que también ha experimentado una contracción significativa, como se observa en el gráfico 6, con las consecuentes pérdidas de empleos. La contracción de los sectores agropecuario y manufacturero representa la pérdida de capacidad de exportación, lo que es crítico en una economía dolarizada.

Gráfico 6. Participación del sector manufacturero en el PIB

\section{ESMANUFACTUE}

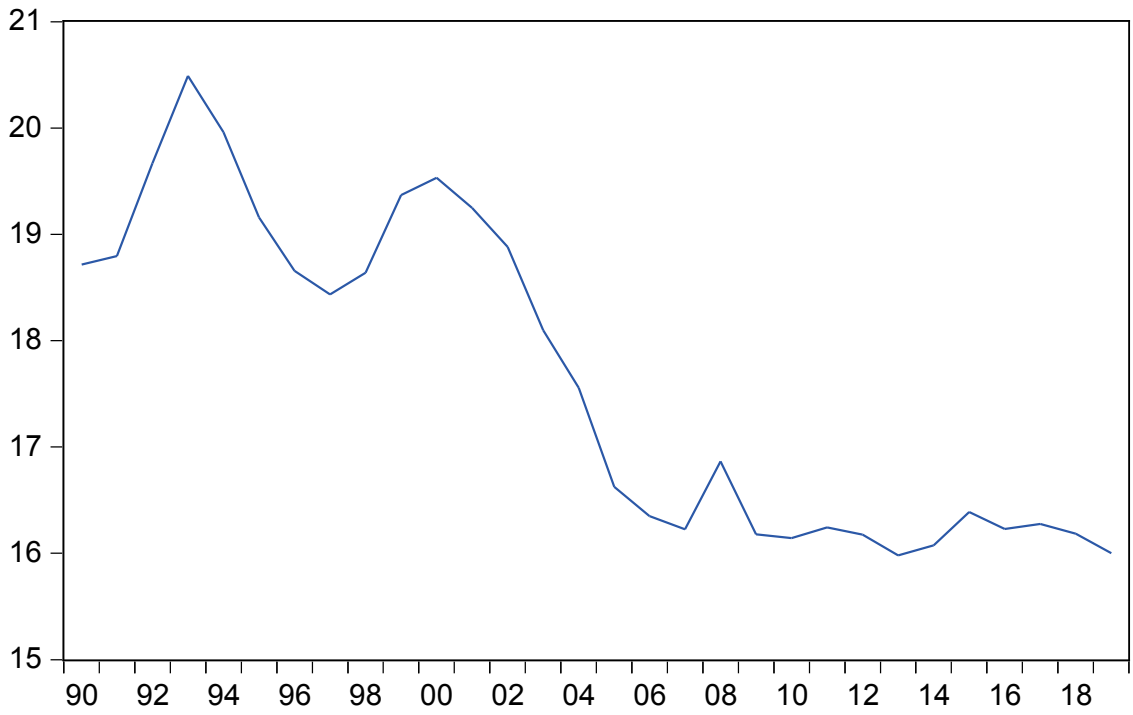

La causa de las contracciones de los sectores manufacturero y agrícola se encuentra en la extrema apertura de la economía salvadoreña, como lo demuestra Cáceres (2017; 2018), apertura que no tenido ningún beneficio para nuestro país.

\section{Importaciones del sector agrícola}

La contracción del sector agrícola ha significado la pérdida de seguridad alimentaria, así como crecientes importaciones de alimentos, y el desplazamiento de trabajadores que han tenido que emigrar a las ciudades o a los EE. UU. La entrada en vigor de la importación libre de impuestos de granos básicos, según lo establece el CAFTA-DR, vendría a profundizar esta tragedia del agro salvadoreño, con mayor intensidad porque estaría afectando a un sector debilitado y acosado por amenazas de varios tipos.

Sumar a esta situación de la agricultura salvadoreña las importaciones de maíz sería un golpe severo a la seguridad alimentaria y al bienestar de las familias de nuestro país. Hay que agregar que, en la actualidad, las importaciones representan cerca de la mitad de la economía salvadoreña, el saldo negativo en la cuenta comercial es cercano en magnitud a las exportaciones y a las remesas, y el consumo privado es superior al PIB, de manera que la tasa de ahorro doméstico es negativa, de $-3 \%$ en 2018 , el único país en América Latina con esta triste distinción.

El gráfico 7 muestra las importaciones de alimentos de El Salvador, donde se aprecia su rápido crecimiento, que constituye un problema de seguridad nacional. 
Gráfico 7. Importaciones de alimentos, 1990-2020

\section{ESIMPORTACIONALIMENTOS}

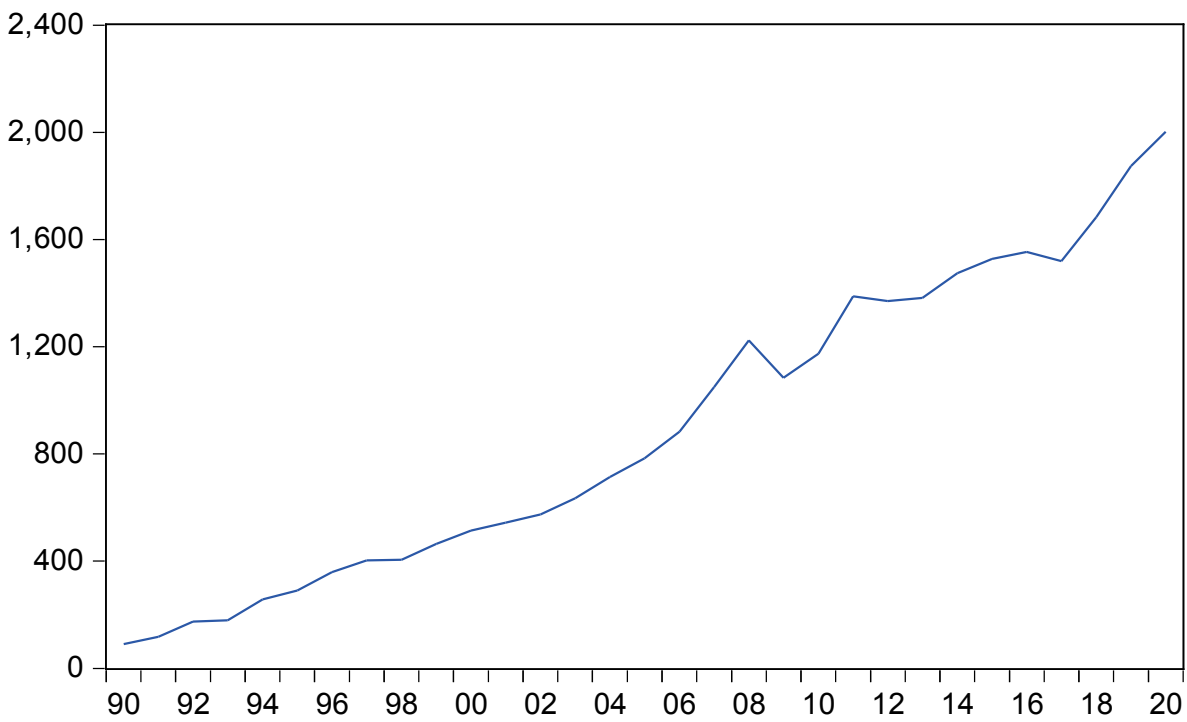

El problema no es el consumo privado en sí, sino que el consumo privado se atiende con importaciones. Estos datos, entre muchos otros, ponen en evidencia la fragilidad de la economía salvadoreña y muestra lo inapropiado que sería permitir la libre importación de granos básicos. Se podría argumentar que la agricultura salvadoreña podría resistir el golpe implicado por el CAFTA-DR por medio del aumento de la productividad, pero esto parece una ilusión al tomar en cuenta que la población rural tiene niveles de educación sumamente bajos, de alrededor de tres años de primaria, que hacen difícil adquirir las destrezas para incrementar la productividad. Además, el aumento de la productividad es un emprendimiento de largo plazo, que se vería frustrado por la dislocación de la producción y el empleo agrícola cuando empiecen a entrar los granos básicos importados.

Hay que tomar en cuenta que las exportaciones de maquila hacia los EE. UU. son una importante fuente de empleo, pero la negociación de la cláusula señalada del CAFTA-DR no quiere decir que esos empleos se van a perder.

\section{Seguridad económica}

Hay que señalar que, a raíz de la pandemia, varios países están llevando a cabo esfuerzos para asegurar la existencia de una oferta mínima de bienes agrícolas e industriales que les otorgue autosuficiencia e independencia de las importaciones; es decir, la oferta de bienes se ha vuelto un elemento de la seguridad nacional. Por lógica y sentido común, El Salvador debe hacer lo mismo.

En este sentido, es del caso hacer referencia a la noticia publicada en el periódico The Washington Post el 4 de marzo de 2021, sobre la política de seguridad nacional adoptada por los EE. UU., que señala: "The Biden administration pledged Wednesday to place American economic security at the center of its decisions about international engagement, trade and the US response to an assertive China...". El periódico añade que el documento que describe la nueva política indica: "Our policies must reflect a basic truth in today's world, that economic security is national security". 
La importación de alimentos, y de muchos otros productos, se ha vuelto posible para El Salvador por las remesas, que se hacen "parche" en las importaciones.

\section{Negociar cambios tratado CAFTA-DR}

Por tanto, es imperativo negociar con los EE. UU. que la cláusula de libre comercio en granos básicos y productos lácteos no entre vigor, ni este año ni en el futuro. Los argumentos se encuentran en que -como se señaló- el país se encuentra en una crisis económica y de salud por la pandemia, experimentó una severa contracción económica en 2020 , severas pérdidas de empleo y aumento de la pobreza, situaciones que se atizarían por la entrada en vigor de esa medida. Además, el cambio climático ha hecho estragos en la agricultura salvadoreña, lo que amenaza la seguridad alimentaria. Así mismo, la agricultura representa un bajo porcentaje de la economía nacional y es conveniente evitar mayores contracciones, que resguarden así el empleo en el sector. Existe también la necesidad de evitar medidas que impulsen la violencia en el país.

Un argumento importante es que la no entrada en vigor de la cláusula de libre comercio en granos del CAFTA-DR estaría evitando el problema para los EE. UU. de tener que enfrentar nuevas corrientes de emigración irregular en su frontera, generadas por el desempleo rural en El Salvador, o mejor dicho en Centroamérica, como fue el caso de México, según lo relata Velut (2011). Se podría suponer que a los EE. UU. no les conviene tener un problema, en su frontera sur, de enfrentar olas de emigrantes irregu- lares resultantes de otra dislocación del agro centroamericano. ${ }^{2}$

La posibilidad de éxito de las negociaciones con los EE. UU. aumentaría si los países centroamericanos y la República Dominicana uniesen esfuerzos para diseñar una estrategia de negociación y hacer planteamientos conjuntos. El punto que se debe recalcar es que los EE. UU. ganan si sus vecinos permanecen en su "barrio", en su hood, y si gozan de los beneficios de economías dinámicas que ofrecen empleos, bienestar y seguridad.

Para promover mejores relaciones con los EE. UU., los países centroamericanos deberían considerar proponer a este, y a México, la creación de una Mesa de Trabajo Conjunto, que se reuniría periódicamente para analizar temas de migración, comercio, cambio climático, gobernabilidad, entre otros, con la modalidad de que, además de la participación de representantes del sector público, participaran también representantes del sector privado, la sociedad civil, la juventud, las mujeres, la población indígena, los afrodescendientes, los académicos. Es decir, se trataría de llevar a cabo "encerronas" para dialogar sobre los problemas particulares de algunos países y otros que son comunes, para planear medidas para superarlos y para que ambas subregiones se conozcan mejor. Esta mesa sería el medio para crear, por medio del diálogo franco, transparente y de buena voluntad, sólidos lazos de amistad duradera, que todos los países necesitan, especialmente los países vecinos.

La negociación es un reto histórico de defender los intereses del pueblo centroamericano, de construir un mejor futuro y garantizar

2 Es del caso citar el artículo "Guatemalans are driven to U.S. border by hunger", publicado en la página A10 de The Washington Post del 3 de abril de 2021, que identifica la inseguridad alimentaria en ese país como la razón del alza de las corrientes de emigración en los últimos meses: "So far this year, more unaccompanied minors processed by immigration agents are from Guatemala than any other country. Analysts and U.S. officials refer obliquely to 'poverty' as an underlying cause of that influx. But often the reason is far more specific: hunger... In interviews with Guatemalans preparing to leave their country and others who have recently arrived in the United States, the majority mentioned food insecurity as a significant factor in their decision to leave. In the western highlands, where a disproportionate number of people are leaving, the rate of chronic child malnutrition hovers around 70 percent, higher than any other country in the world". 
la paz social, lo que tiene muchos beneficios para los países vecinos, particularmente para México y los EE. UU. Es el momento de responder al llamado de la historia.

\section{Remesas y tarifa a importaciones}

Hay que señalar que la contracción de los sectores agrícola y manufacturero está relacionada con la exportación de gente. Las remesas son un indicador de la cantidad de gente que ha salido del país; el gráfico 8, construido con datos de 1991-2018, muestra que a medida que los sectores productivos iban decreciendo, las remesas (como porcentaje del PIB) aumentaban. Es decir, la pérdida de empleos en estos sectores condujo a una emigración como recurso de sobrevivencia, que se refleja en la entrada de remesas al país.

Gráfico 8. Sectores productivos (esmanufactue+esagricultura) y remesas como porcentaje del PIB (esremesas)

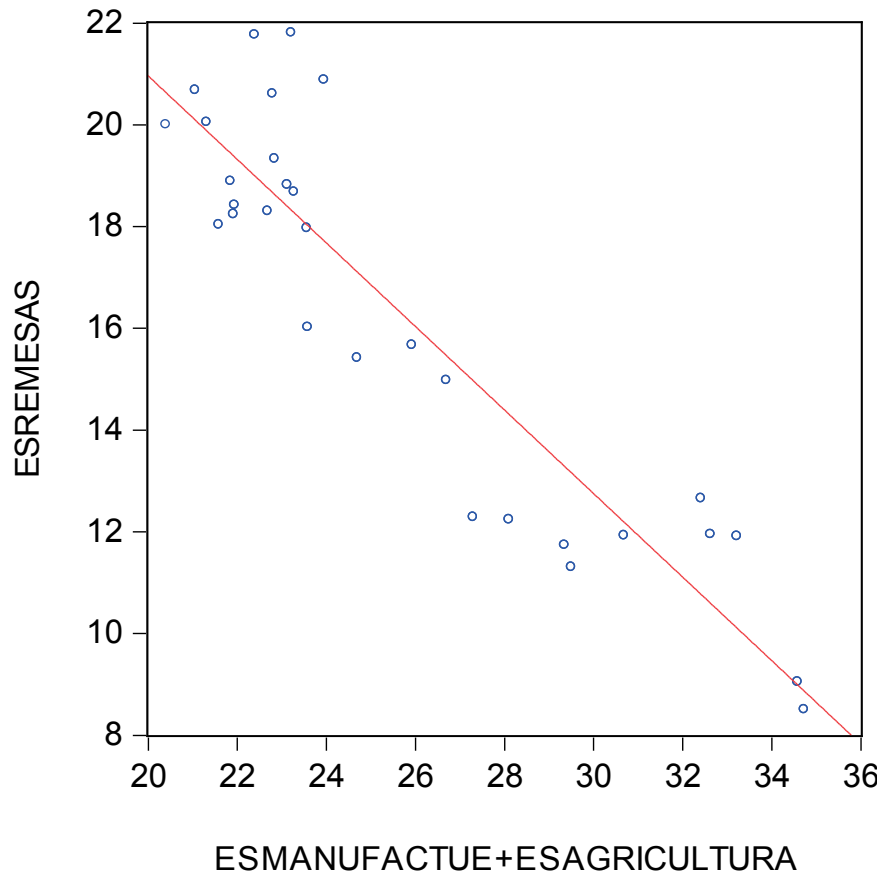

Hay que recalcar que la contracción de los sectores productivos ha sido el resultado de la liberalización del comercio exterior, o sea, de la desmedida apertura económica; el gráfico 9 muestra que la reducción de la tarifa a las importaciones condujo a la caída de la participación de los sectores agropecuario y manufacturero en el PIB. 
Gráfico 9. Tarifa a importaciones y sectores productivos (esmanufactue+esagricultura)

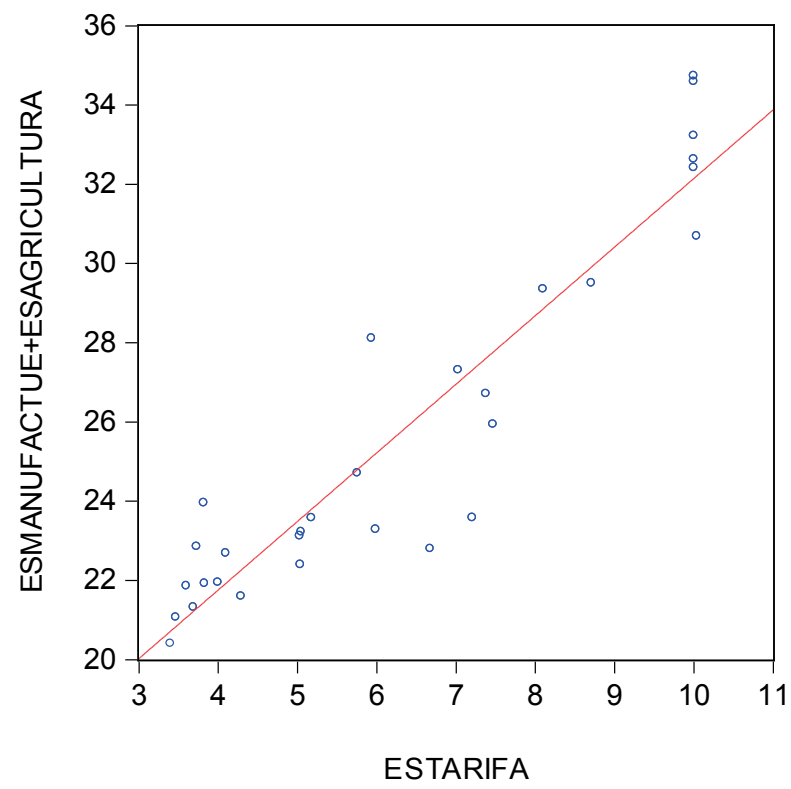

De los dos gráficos anteriores, se deduce que la reducción tarifaria guarda relación negativa con las remesas, es decir, a mayor protección, más bajas son las remesas como porcentaje del PIB (gráfico 10).

Gráfico 10. Tarifa a las importaciones y remesas como porcentaje del PIB (esremesas)

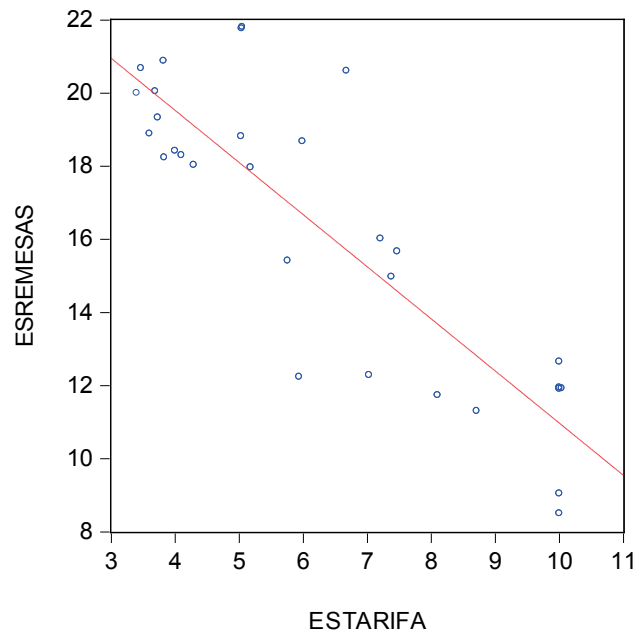


Mientras que los cuentos del Tío Coyote mantienen que la liberalización comercial es un medio para impartir competitividad a las empresas y así potenciar sus exportaciones, lo que ha ocurrido en El Salvador es que la apertura ha conducido a la exportación de gente.

Por otra parte, el déficit en la cuenta comercial, EsImports-EsExports, también ha aumentado simultáneamente con la reducción de la tarifa, como se observa en el gráfico 11. Varios autores han señalado que la principal manifestación de la liberalización del comercio exterior han sido los elevados déficits en la cuenta comercial de la balanza de pagos (Stiglitz 2003; Santos-Paulino y Thirlwall, 2004).
El total de las remesas no son suficientes para financiar este déficit, por lo que se debe recurrir a otras fuentes de recursos externos, principalmente a la deuda externa. Esto hace ver que la dinámica del endeudamiento externo obedece a la excesiva apertura de la economía salvadoreña.

\section{Ahorro interno}

Hay que observar la caída del ahorro interno en el periodo 1990-2018, en la que sobresalen los valores negativos que predominan después de mediados de los años noventa, que indican que el consumo total supera el PIB. Esto es un first en los anales de las economías latinoamericanas (gráfico 12).

Gráfico 12. Tasa de ahorro interno

\section{ESAHORROINTERNO}

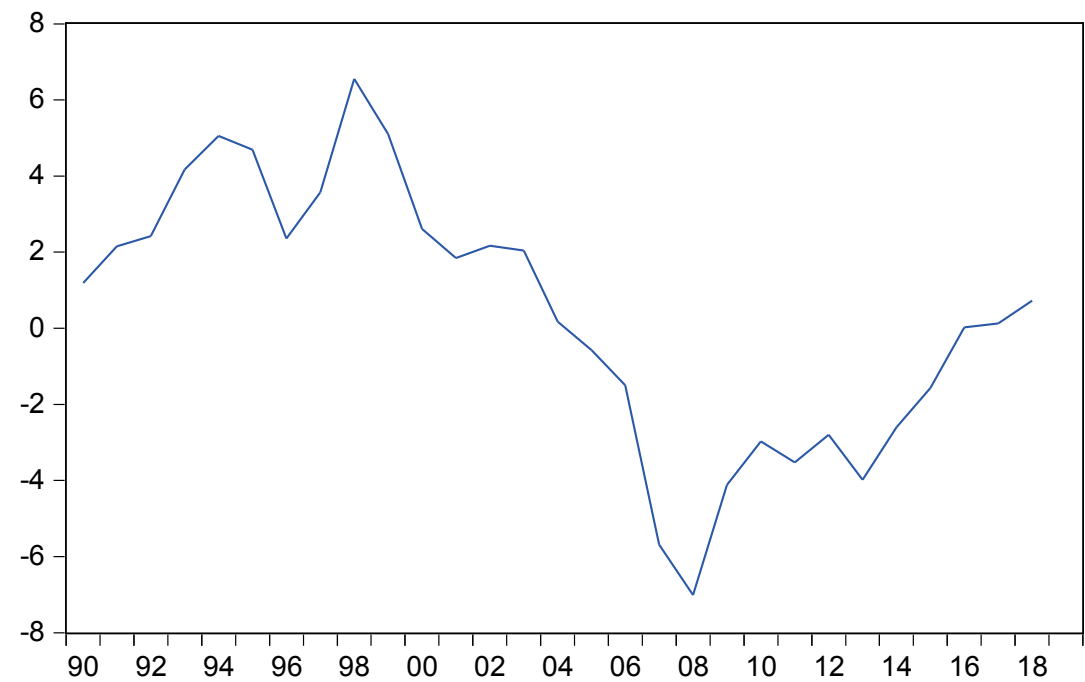

La caída del ahorro interno se puede asociar a la reducción de las tarifas a las importaciones, que se observa en el gráfico 13. 
Gráfico 13. Tarifa a las importaciones y tasa de ahorro interno

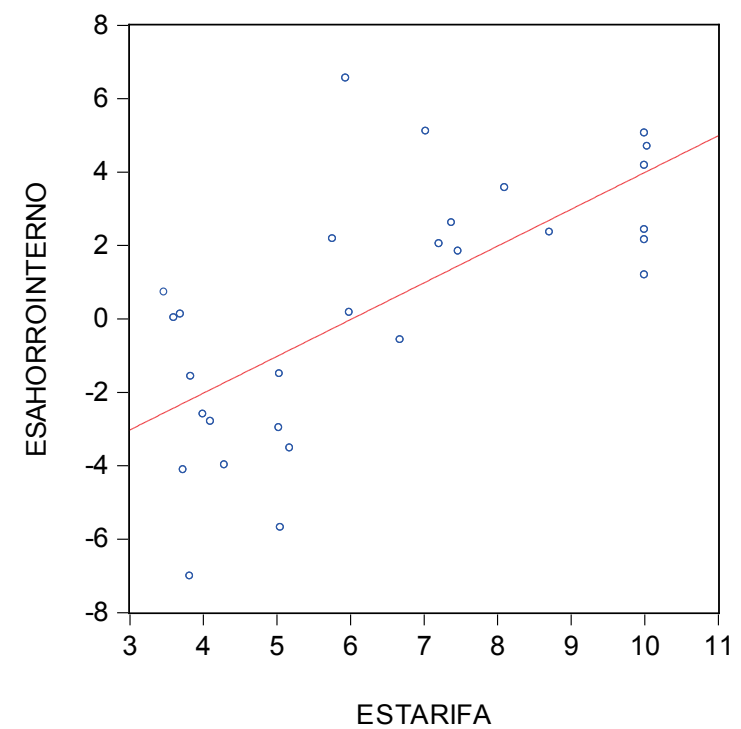

Ante los elevados déficits en la cuenta comercial, la medida recomendada para otros países sería recurrir a un régimen de tipo de cambio flexible para contener las importaciones; esto no es posible en nuestro país, ya que se recurrió a la dolarización.
Hay que señalar que la tarifa tiene una relación negativa con la tasa de crecimiento económico, lo que se explica por la contracción de los sectores productivos y la caída del ahorro, a raíz de la apertura desmedida (gráfico 14).

Gráfico 14. Tarifa y tasa de crecimiento económico

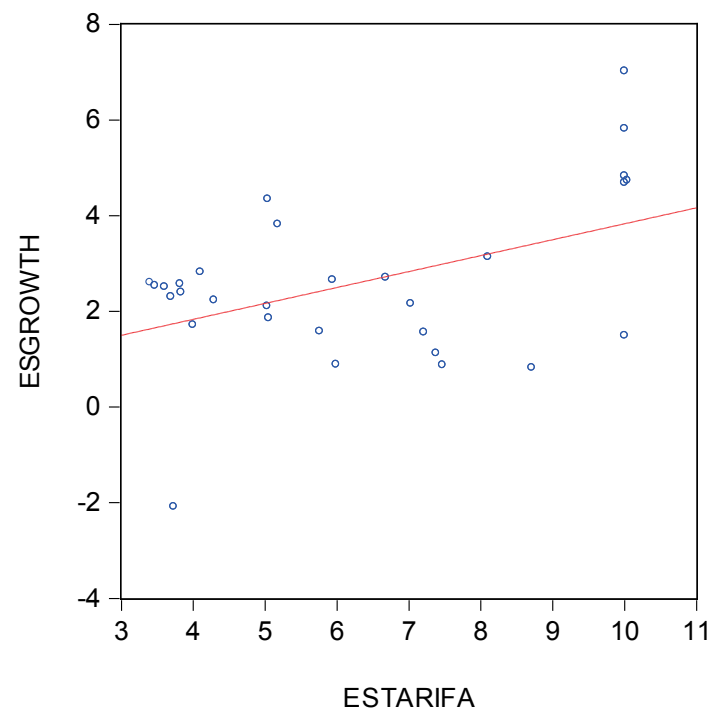




\section{Apertura y violencia}

La contracción de los sectores productivos, y la resultante tendencia al estancamiento de la economía salvadoreña, han conducido a la escasez de empleos, que se manifiesta no solo en la expulsión de gente, sino también en el aumento de homicidios. Datos de 2010 de 13 países latinoamericanos, tomados de Hoyos, Rogers y Popova (2015), permiten apreciar que existe una relación positiva entre el déficit en la cuenta comercial y el número de homicidios por 100,000 personas, ${ }^{3}$ como se muestra en el gráfico 15.

Gráfico 15. Déficit en la cuenta comercial en 2010 y número de homicidios por 100,000 personas (promedio 2008-2012)

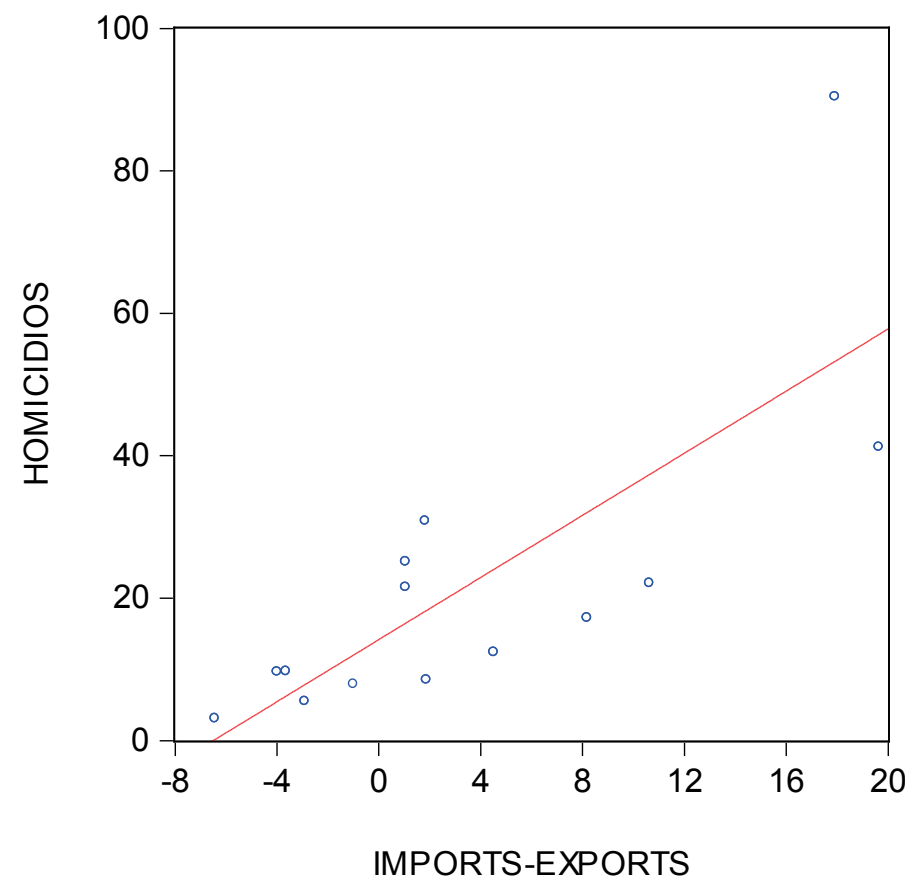

No extraña que, como se muestra en el gráfico 16 , existe en los países latinoamericanos una relación positiva entre el número

de personas de ambos sexos que están en la cárcel (por 100,000 habitantes) y la apertura económica.

3 Los datos de homicidios por 100,000 personas fueron tomados del Reporte del Desarrollo Humano 2016, del PNUD. 
Gráfico 16. Déficit en la cuenta comercial y número de personas en la cárcel

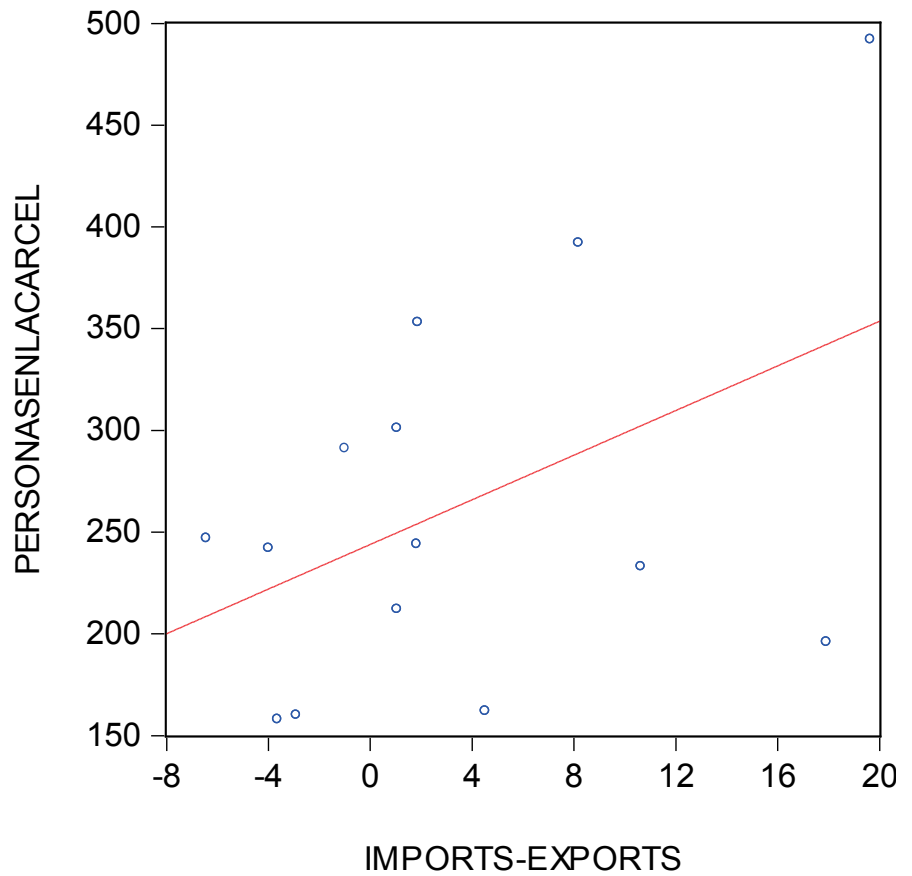

La discusión anterior hace ver que los problemas de la economía salvadoreña han sido hechos en casa; son resultado de medidas que, en retrospectiva, aparecen como asaltos a la razón y al bienestar de la sociedad salvadoreña.

\section{Políticas económicas}

Es necesario considerar las medidas de política macroeconómica que se deben implementar para contrarrestar el comportamiento de la economía salvadoreña descrito en los párrafos anteriores. Hay que tener presente que, mientras la economía mantenga la apertura excesiva y el irracional consumo privado, no habrá solución al problema del estancamiento económico.

\section{Aumentar la protección a sectores productivos}

La medida que se presenta como de mucho valor es el incremento de la protección a los sectores productivos. Esto podría sonar como una herejía después de décadas de noticias falsas sobre las "bondades" del libre comercio; hay que tomar en cuenta que los países ahora desarrollados recurrieron a la protección para impulsar su industrialización y despegue económico. Un ejemplo alentador es la medida reciente tomada en los EE. UU. de aumentar las tarifas a productos importados de determinados países.

Con miras a apreciar los efectos del aumento de las tarifas, se estimaron modelos VAR, primero con las variables tarifa, los porcentajes que el sector agropecuario representa en el PIB, y las tasas de empleo femenino y masculino en ese sector, con resultados que se muestran en el gráfico 17. Este gráfico permite apreciar que la protección puede ser efectiva para incrementar el valor agregado de la producción agrícola y el empleo en el sector. 
Gráfico 17. Respuesta del sector agropecuario y del empleo femenino y masculino en ese sector a aumentos de una desviación estándar de la tarifa a las importaciones

Accumulated Response to Cholesky One S.D. Innovations \pm 2 S.E.

Accumulated Response of ESAGRICULTURA to ESTARIFA

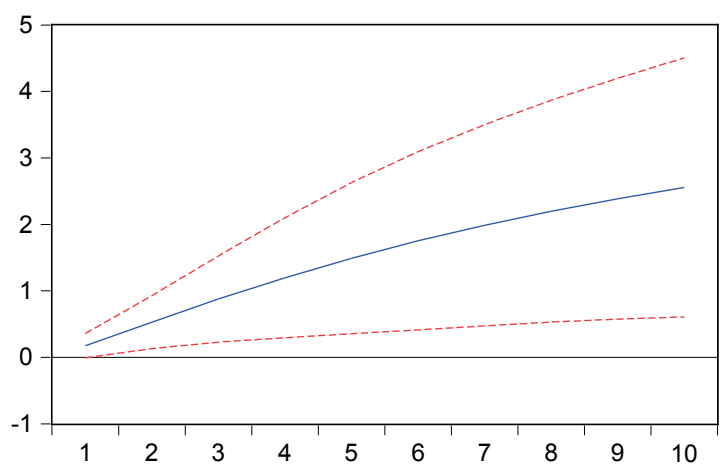

Accumulated Response of ESEMPLEOAGRMASC to ESTARIFA

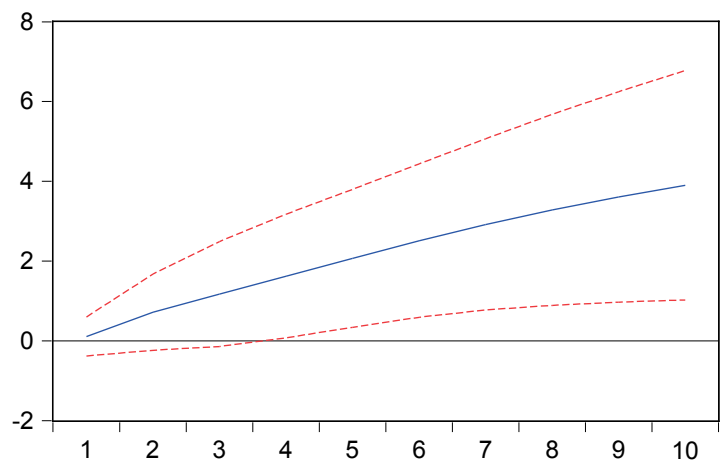

Accumulated Response of ESEMPLEOAGRIFEME to ESTARIFA

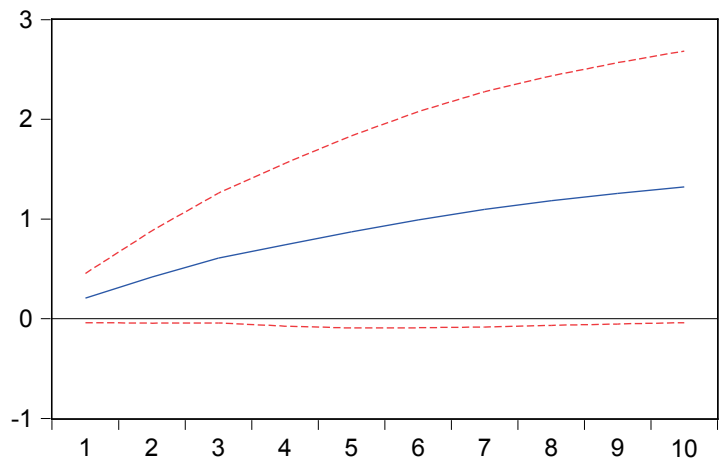


Se estimó otro VAR que muestra que el aumento de la tarifa conduciría al aumento de las tasas de empleo femenino y masculino en el sector manufacturero (gráfico 18).

Gráfico 18. Aumento de tarifa y tasas de empleo femenino en el sector manufacturero

\section{Accumulated Response of ESEMPLEOINDUSTRIAFEME to Cholesky One S.D. ESTARIFA Innovation}

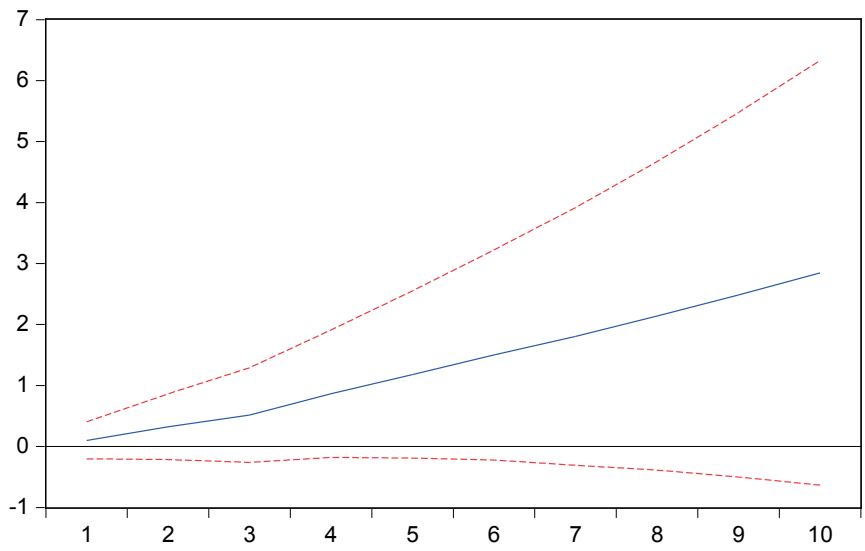

\section{Aumentar ingresos tributarios}

Otra medida que indudablemente puede ser de mucho beneficio para revertir el deterioro económico es el aumento sustancial de los ingresos tributarios con miras a incrementar el gasto social en educación, salud y desarrollo rural. Esta sería una medida valiosa para combatir la violencia, en vista de la relación negativa entre la tasa de homicidios anuales por 100,000 personas y el gasto público en educación como porcentaje del $\mathrm{PIB}$, que se muestra en el gráfico 19.

Gráfico 19. Gasto público en educación como porcentaje del PIB y tasa de homicidios

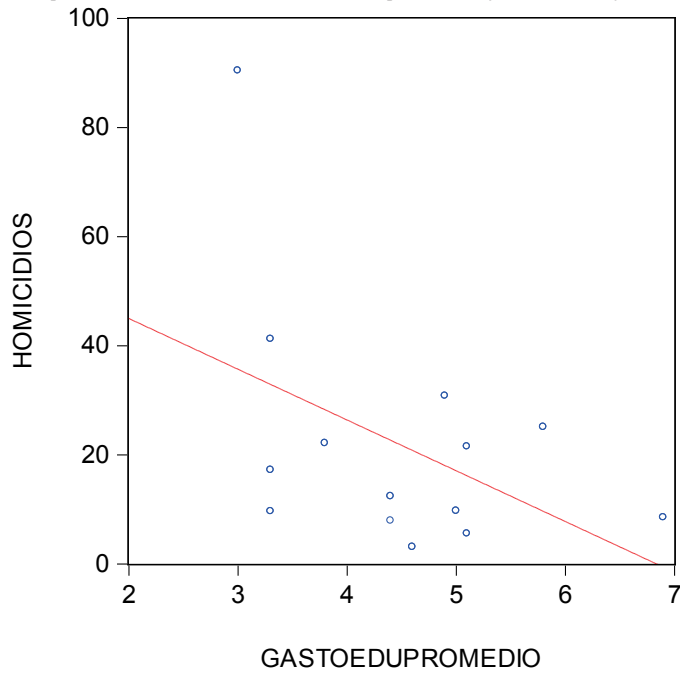


Dado que la Constitución de la República está en proceso de revisión, esta debería ser la oportunidad para establecer que el gasto en educación y en salud como porcentajes del PIB no estarán por debajo de 7.5 y $5 \%$, respectivamente.

Hay que hacer referencia al pronunciamiento de la directora gerente del Fondo Monetario Internacional que en declaraciones, el 1 de abril de este año, recomendó que los países incrementen sus ingresos fiscales aumentando los impuestos a los contribuyentes más ricos, para así estar en la capacidad de atender decididamente las necesidades de los estratos más pobres. En el mismo sentido, economistas de esa institución (Cárdenas et al., 2021) han recomendado que los países latinoamericanos mantengan los altos niveles de gasto social que han resultado de sus respuestas ante la pandemia $y$, además, que incrementen la tributación aumentando los impuestos, lo cual podría llevarse a cabo en el marco de un pacto fiscal. $^{4}$

\section{Casos de Panamá y Ecuador}

Hay que hacer referencia a Panamá y Ecuador, países que han mostrado las más altas tasas de crecimiento económico en la última década, a pesar de que son dolarizados. La razón se encuentra en que las tasas de ahorro nacional de estos países son sumamente elevadas, de alrededor de $30 \%$, lo que les ha permitido alcanzar tasas de inversión de alrededor de $33 \%$ y, en consecuencia, sus economías han mostrado singular dinamismo.

$4 \quad$ El documento del FMl exhorta a los países latinoamericanos a que adopten pactos fiscales como medio para incrementar la recaudación tributaria y atender con la más alta prioridad los sectores que la sociedad considera prioritarios, ya que en su ausencia "the continuation of low growth, social discontent, and political polarization might drive Latin America towards a very dangerous path of institutional and economic decay. Catalyzing such changes would require a broad social consensus and political cohesion around several crucial dimensions of public finances: a fiscal pact" (p. 4). El documento aboga por:

"Once the pandemic is under control, countries should improve social protection by revising access to pensions, health, and educational systems as well as reforming the tax framework to increase revenues (in the cases where this is needed) and deliver a higher degree of progressivity from public finances in the region... These are the main areas a renewal of the social contract would contribute to more equitable and sustainable public finances" (p. 26).

El documento concluye así: "a social dialogue on how to broaden the social safety net and how to finance it, to access society's preferences regarding the tax and expenditure implications behind these very consequentials tradeoffs. The public dialogue should serve as a basis into the legislative process that should take place in the next couple of years to revise pensions, health, and educational systems as well as reforming tax frameworks to support it" (p. 35). 
Gráfico 20. Tasas de ahorro interno de Ecuador y Panamá y El Salvador

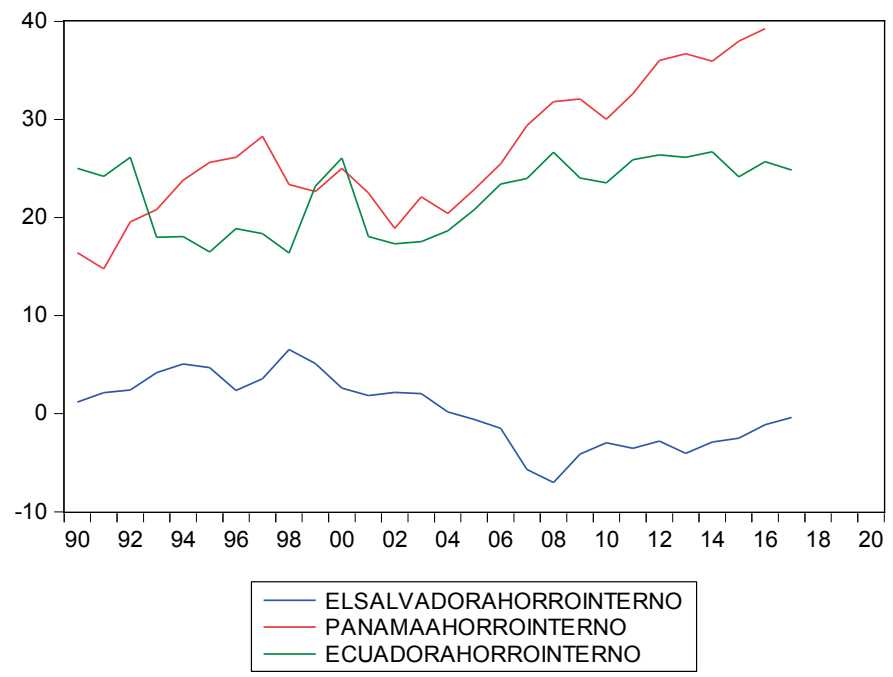

Esto no implica que la dolarización fue una sana medida para la economía salvadoreña; al contrario, es la más desdichada de las decisiones de la historia económica de nuestro país, que pone en evidencia las prácticas del abuso y atropello contra la sociedad salvadoreña, y es un verdadero caso de lo que la CEPAL (2018) ha llamado la "cultura del privilegio". Así mismo, también califica dentro del ámbito de la "economía de la crueldad", en el sentido de Krugman (2020).
Al observar los casos de Panamá y Ecuador, la deducción clara es la importancia de aumentar el ahorro en El Salvador para parar la grande bouffe.

Otra área que podría ser de valor es el emprendimiento. Esta actividad ha adquirido importancia en nuestro país, pero todavía el número de empresas registradas cada año por 1,000 habitantes es bajo en relación con otros países vecinos, como se observa en el cuadro siguiente.

Cuadro 1. Número de empresas registradas por año

\begin{tabular}{|l|l|l|l|l|}
\hline \multicolumn{1}{|c|}{ El Salvador } & \multicolumn{1}{c|}{ Año } & \multicolumn{1}{c|}{ México } & \multicolumn{1}{c|}{ Costa Rica } & \multicolumn{1}{c|}{ Guatemala } \\
\hline & 2006 & 0.327076 & 1.70921 & 0.667523 \\
\hline & 2007 & 0.381485 & 2.182005 & 0.661738 \\
\hline & 2008 & 0.386097 & 2.370342 & 0.710772 \\
\hline & 2009 & 0.535925 & 1.368584 & 0.64042 \\
\hline 0.486563 & 2010 & 0.617302 & 1.630406 & 0.612498 \\
\hline 0.460281 & 2011 & 0.598499 & 1.388418 & 0.597166 \\
\hline 0.49762 & 2012 & 0.407312 & 0.906616 & 0.475549 \\
\hline 0.499369 & 2013 & 0.549402 & 0.910948 & 0.504426 \\
\hline
\end{tabular}




\begin{tabular}{|l|l|l|l|l|}
\hline 0.517638 & 2014 & 0.553973 & 1.129266 & 0.49206 \\
\hline 0.531439 & 2015 & 0.577269 & 1.42734 & 0.504706 \\
\hline 0.539926 & 2016 & 0.557476 & 2.073426 & 0.47951 \\
\hline 0.521238 & 2017 & 1.006919 & 2.159178 & 0.552115 \\
\hline 0.56601 & 2018 & 1.00407 & 2.599624 & 0.527748 \\
\hline
\end{tabular}

La importancia de estos datos reside en la evidencia de que la creación de empresas es un determinante del crecimiento económico, como lo han reportado varios autores, principalmente para países europeos (Carree \& Thurik, 2002; Bosma et al., 2018), y como lo demostrado Cáceres (2021) para México y Centroamérica.

\section{Portal de los economistas}

Llama la atención que, a pesar de sus persistentes tendencias al estancamiento, la problemática de la economía salvadoreña no ha sido objeto de debate, salvo algunos casos recientes. Es decir, es una situación que hemos llegado a aceptar con resignación, tal vez bajo la ilusión de emigrar, o como dice Benedetti, de "alguna lotería". Esto puede ser un reflejo de la polarización política existente en nuestro país, que hace que las opiniones en materia económica sean descartadas como manifestaciones de intereses doctrinarios o políticos. Pero de continuar el estancamiento y la falta de oportunidades de empleo, agravados por la pandemia del COVID-19, el futuro podría traer una verdadera catástrofe.

Habría que hacer un gran esfuerzo para promover la diseminación de puntos de vista en temas relacionados con la economía de nuestro país, y con la centroamericana, por profesionales de todas las orientaciones, ya sean "monetaristas", "keynesianos", "kaleskianos", entre otros, y de todas las orientaciones políticas, sea de "derecha", "izquierda", "centro", "socialdemócrata", "independiente", etc.
Para estos propósitos, se plantea la creación de un Portal de los Economistas Salvadoreños (¿Centroamericanos?), donde estos tendrían espacio para adjuntar sus blogs, organizar webinars y conferencias magistrales, y para llevar a cabo periódicamente tribunas abiertas con la participación del público en general.

El objetivo sería incrementar la comunicación entre los profesionales, practicantes y estudiantes de las ciencias económicas; elevar la categoría intelectual de la profesión; incrementar el conocimiento y la amistad entre los economistas $y$, en especial, no dejar que las opiniones vertidas en campos pagados y en noticias falsas acaparen la opinión sobre temas de la economía salvadoreña.

Una universidad del país podría actuar como coordinadora del portal, dando mantenimiento al mismo, actuando como web master, promoviendo la incorporación de profesionales e interesados al sistema y estableciendo los calendarios de actividades.

\section{Referencias bibliográficas}

Bosma, N., Content, J., Sanders, M. \& Stam, E. (2018). Institutions, Entrepreneurship, and Economic growth in Europe. Small Business Economics, 51, 483-499. https://link.springer.com/ article/10.1007/s11187-018-0012-x

Cáceres, L. R. (2017). Deindustrialization and Economic Stagnation in El Salvador. Revista de la CEPAL, 122, 58-77. https://repositorio.cepal.org/bits- 
tream/handle/11362/42659/RVI122 Caceres.pdf? sequence $=1 \&$ isAllowed $=y$

Cáceres, L. R. (2018a). Desindustrialización, trabajo y violencia en El Salvador. Revista de la CEPAL, 125, 191-223. https://repositorio.cepal.org/bitstream/ handle/11362/43997/1/RVE125_Caceres.pdf

Cáceres, L. R. (2018b). La juventud que ni trabaja ni estudia en América Latina (sin publicar).

Cáceres, L. R. (2021). Emprendedurismo y crecimiento económico en México y Centroamérica (sin publicar).

Cárdenas, M., Ricci, L. A., Roldós, J. \& Werner, A. (2021). Fiscal Policy Challenges for Latin America during the Next Stages of the Pandemic: The Need for a Fiscal Pact. IMF Working Paper, 21/77, 1-40. https://www. imf.org/en/Publications/WP/Issues/2021/03/17/ Fiscal-Policy-Challenges-for-Latin-Americaduring-the-Next-Stages-of-the-Pandemic-TheNeed-50263

Carree, M. A. \& Thurik, A. R. (2002). The Impact of Entrepreneurship on Economic growth. En Z. Acs \& D. Audretsch (Eds). International Handbook of Entrepreneurship Research (pp. 557-594). Springer.

CEPAL (2018). La ineficiencia de la desigualdad. https://www. cepal.org/sites/default/files/publication/files/43442/S1800059_es.pdf

Floyd, D. (2020). NAFTA's Winners and Losers. Investopedia. https://www. investopedia.com/articles/economics/08/ north-american-free-trade-agreement.asp

Krugman, P. (2020). Arguing with Zombies: Economics, Politics, and the Fight for a Better Future. W. W. Norton and Company.

Santos-Paulino, A. \& Thirlwall, A. P. (2004). The Impact of Trade Liberalization on Export Growth, the Balance of Trade and the Balance of Payments in Developing Countries. The Economic Journal, 114(496), F50-F2. https://www.jstor.org/stable/3590110
Stiglitz, J. (2003). El rumbo de las reformas: hacia una nueva agenda para América Latina. Revista de la CEPAL, 80, 7-40. https://repositorio.cepal.org/bitstream/ handle/11362/10893/1/080007040_es.pdf

Velut, J.-B. (2011). NAFTA's Developmental Impact on Mexico: Assessment and Prospects. IdeAs. Idées d'Amériques, 1 , 1-23. https://journals.openedition.org/ideas/71

\section{Anexo I}

\section{Inversiones en los sectores productivos}

En los tres anexos a continuación, se presentan varias ideas de iniciativas que podrían contribuir a la reactivación del sector productivo nacional, especialmente el café. Es alentador que el Gobierno haya puesto en marcha el Plan de Transformación y Despegue Sostenido del Café 2020-2024 que, sin lugar a dudas, vendrá a contribuir de manera significativa a la reactivación de este importante rublo. Lo que se propone aquí puede ser complemento de las acciones comprendidas en dicho plan.

Ante la contracción del sector agropecuario nacional, las importaciones han ido incrementando su papel de atender la demanda de consumo de bienes agropecuarios en el mercado doméstico, a tal grado que se observa en la actualidad una vergonzosa dependencia de las importaciones de muchos bienes que en el pasado abundaban en la campiña salvadoreña, como los aguacates, nances y hasta jocotes, lo que no deja de despertar la pregunta sobre el grado de desidia y mediocridad a que hemos llegado.

Lejos de aceptar la entrada de granos básicos libre de impuestos, la realidad demanda emprender esfuerzos para reactivar el sector agrícola, ofreciendo adecuadas ofertas de crédito y de asistencia técnica y, particularmente, preparando estudios de base para la inversión en nuevos cultivos. El punto de partida debería ser promover el cultivo de bienes agrícolas que son actualmente 
importados, especialmente flores, verduras, naranjas, aguacates, tamarindos, marañones, uvas, manzanas, así como queso y otros productos lácteos. Hay que preguntarse por qué Honduras exporta hacia los EE. UU. melones, sandías y naranjas, mientras $\mathrm{El}$ Salvador los importa. Costa Rica y Nicaragua son exportadores también a ese país de plátanos, maní, palmito, macadamia, semilla de marañón, pistachos, mientras que nosotros a duras penas exportamos café. Las preguntas son: ¿dónde están los capitalistas? ¿Dónde están los animal spirits de los emprendedores? ¿Será que las noticias falsas de la globalización y de la apertura, junto con la comida chatarra, las películas de muñequitos y las "redes", nos ha provocado un caso serio de lobotomía lateral, integral y enteritis?

En El Salvador, hay tierras ociosas en abundancia, hay todavía mano de obra; entonces, con miras a promover la inversión, se debería diseñar una hoja de ruta para la reactivación del sector. En ese marco, la creación de trading companies podría ser valioso, así como la creación de empresas agrícolas capitalizadas con la venta de acciones de baja denominación para permitir las inversiones de muchas personas. Otra modalidad podría ser recurrir a la titularización de los futuros ingresos de las empresas agrícolas a ser creadas, como se hace en la titularización de bienes raíces.

Especial importancia radica en la creación por caficultores salvadoreños de empresas comercializadoras de café, que exportarían el grano bajo criterios de calidad y de distribución de ganancias entre los accionistas. Estas empresas también podrían establecer otras empresas en el extranjero, por ejemplo, en los EE. UU., Canadá, Japón, Corea y China, para tostar, procesar y vender el café que ellas mismas importarían. Es decir, lo que se buscaría es la participación de los productores nacionales en las áreas de máxima rentabilidad, que son la tostaduría, el molido, el empaque, la comercialización y la venta al por menor, mediante la apertura de cafeterías; o sea que se trataría de crear "estarbocs" salvadoreños que operan en otros países. Esto puede parecer demasiado ambicioso, pero si dejamos de lado la patética racha de inercia y conformismo que nos embate, sí es posible.

El asunto es retomar el espíritu de inversión que hace décadas caracterizaba al pueblo salvadoreño, encontrar de nuevo la garra, el "ñeque", la audacia, la valentía.

\section{Anexo II}

\section{Hacia la promoción de la caficultura por medio de la emisión de una moneda electrónica}

El Ministerio de Salud de Costa Rica, junto con la empresa Próxima Comunicación, lanzó recientemente una iniciativa para proteger el medio ambiente consistente: primero, en una campaña para que los hogares clasificaran su basura y sus desechos en varias categorías, ya sea metal, desecho de comida, plástico, vidrio, etc., $y$, segundo, para que los hogares transportaran tales desechos a centros de colección, en donde serían cambiados, en pago, por determinadas cantidades de una moneda virtual, el eColón.

Para llevar a cabo esta transacción, la persona que vendiera sus desechos tendría que registrarse en un determinado sitio en la web y abrir una cuenta electrónica en donde se le depositarían los eColones.

Con las cantidades acumuladas en su cuenta, la persona participante puede pagar parcialmente por bienes y servicios vendidos por empresas participantes, en las que sobresalen salas de cine y de teatro, hoteles, librerías y otros (véase el sitio eColonescr.com). Este sistema ha sido replicado en Panamá con la emisión de la moneda virtual eCoins (véase panamá.ecoins.com).

A continuación, se propone que en $\mathrm{El}$ Salvador se emule esta experiencia de Costa Rica y Panamá, mediante el diseño e implementación de un sistema similar orientado a la protección del medio ambiente y a la reactivación de la caficultura, que consistiría en el sistema siguiente: 
Un ente encargado del sistema emitiria una moneda virtual (llamada la eArbor, o podría llamarse la eTerra). Esta moneda sería un medio de pago otorgado a caficultores a cambio de la siembra de árboles de café (plantillas) o árboles de sombra o de madera.

Esto implica que se establecería una relación entre el número de los árboles (o las manzanas) sembrados y el pago en eArbors. Estos pagos virtuales se llevarían a cabo después de rigurosas inspecciones de las plantaciones por el ente encargado.

Para participar en el sistema, el productor de café deberá registrarse y abrir una cuenta electrónica en la que se le depositarían los eArbors.

Habría que desarrollar una campaña para motivar a empresas comerciales para que participen en el sistema. Y, así mismo, habría que negociar con las empresas el monto máximo que aceptarían en pago parcial por los artículos que vendan a los productores de café (los que pagarían, parcialmente, con la moneda virtual).

A cambio de su adhesión al sistema, las empresas comerciales podrían recibir el compromiso del ente encargado de publicar periódicamente en los medios de comunicación campos pagados que destaquen las empresas "comprometidas con el medio ambiente, el agua, la caficultura y la familia salvadoreña".

Sería del caso considerar que los eArbors se usarían para hacer pagos para reducir los saldos pendientes ante las empresas exportadoras de café y para la cancelación parcial de las deudas con el FICAFE.

El sistema descrito vendría a contribuir a generar una fuente adicional de ingresos a los productores de café, que tiene especial importancia ante la actual problemática de los precios, a la vez que contribuiría a la protección y rehabilitación del medio ambiente y de los mantos de agua.

Es decir, las actividades de resiembra de los productores de café generan beneficios más allá de los que ellos mismos reciban, ya que la sociedad salvadoreña como un todo se beneficia.

Pero las sociedades de otros países se benefician también, ya que el bosque salvadoreño (y el de Centroamérica) tiene un gran papel en enfriar el mar Caribe y, por tanto, en reducir las probabilidades de huracanes y tormentas tropicales que se han incrementado sustancialmente en el Caribe y han incidido de manera negativa en los EE. UU. Además, el bosque de café ha sido el hábitat predilecto de las aves migratorias de este país y de Canadá, que hacen paradas en las montañas de cafetales de El Salvador, en su ruta de invierno hacia América del Sur, para luego, en tiempos de la primavera, regresar a los países de origen y deleitarse comiendo insectos en los campos de trigo.

Lo anterior hace ver la conveniencia de que la caída del bosque y del cultivo del café es un problema que incide de manera global y que llama a los países desarrollados a participar en su rehabilitación.

Por tanto, se podría considerar que los eArbors serían recibidos por instituciones $\mathrm{u}$ organismos no gubernamentales de cooperación, pagando en efectivo. Entre estas instituciones, se encuentran Catholic Relief Services, Open Society Foundations (Soros) y Save the Children. Estas instituciones podrían eventualmente donar sus eArbors a instituciones benéficas nacionales.

Otra modalidad que se podría considerar es que el Gobierno aceptara de los individuos y las empresas los eArbors como pago parcial de su impuesto a la renta, recibiéndolos al valor nominal. Posteriormente, el Gobierno podría vender los eArbors así adquiridos en el mercado secundario con un descuento de, por ejemplo, $20 \%$. El comprador podría usar la moneda virtual como pago en la compra de bienes y servicios de las empresas participantes, las que recibirían la moneda virtual al valor nominal.

También es de interés emular las experiencias de Costa Rica y Panamá en el sistema 
de pagos en monedas virtuales por la basura recolectada.

\section{Anexo III}

\section{Portal de negocios y comercio para el café de El Salvador}

\section{Antecedentes}

La reactivación de la caficultura salvadoreña requiere de grandes esfuerzos en materia de producción y comercialización. En los párrafos siguientes, se presenta una propuesta de diseño de un portal electrónico para la promoción y venta de café salvadoreño, lo que se considera sería un medio valioso para incrementar las ventas del grano en el mercado nacional e internacional.

Las tecnologías de información y comunicaciones (ICT) están permitiendo en forma acelerada la transformación de muchos aspectos de la actividad económica en todo el mundo, en la manera como se vinculan las empresas entre sí, y con sus clientes, facilitando los flujos de capital y las transacciones entre distintas latitudes del mundo.

En este sentido, resalta la creación de "mercados virtuales" que están alcanzando a las masas críticas de vendedores y compradores, con excelentes resultados a nivel mundial, como es el caso de Alibaba (http:// www.alibaba.com), con 4.8 millones de miembros en 240 países y más de US $\$ 3,000$ millones en transacciones durante 2005.

En el diseño de un portal para el café de El Salvador, es de especial importancia que participen todos los segmentos de productores, grandes y pequeños, así como cooperativas, de manera que los beneficios sean palpables en todos los estratos de la sociedad. Esto es de especial importancia para los pequeños productores, dado que enfrentan dificultades muy particulares para exportar, en términos de no contar con conocimientos de mercados, ni de las regulaciones relacionadas con la exportación, a la vez que sus recursos para fines de mercadeo son reducidos. De allí la conveniencia de establecer sistemas electrónicos que permitan que todas las empresas tengan igualdad de oportunidades para colocar sus productos en el exterior.

Los modelos de "mercados virtuales" constituyen respuestas valiosas a las necesidades de los productores de café. La estructuración de un "mercado virtual" de café para los productores (grandes, pequeños y micro) y las cooperativas facilitaría las transacciones comerciales, lo que podría traducirse en mayores volúmenes de exportaciones y de ventas en el mercado nacional, al generar beneficios en términos de la mayor accesibilidad a los mercados de los EE. UU., de los países asiáticos y europeos a todas las empresas productoras de café participantes, y así dar lugar a la reducción de los costos de transacción. A continuación, se presenta una propuesta para el diseño e implementación de una plataforma que permita el acceso de empresas $e$ individuos salvadoreños productores de café a los mercados nacional $e$ internacionales y que, en términos generales, contribuya a la generación de ventas crecientes de café y sus derivados.

\section{Objetivo general}

El objetivo general radica en apoyar la recuperación de la caficultura salvadoreña, mediante la puesta en marcha de una herramienta tecnológica que facilite la promoción y la venta de café en todo el mundo.

\section{Objetivos específicos}

Apoyar a los propietarios de fincas y a cooperativas en términos de otorgarles una herramienta en la internet, con información y servicios relevantes que faciliten la promoción y divulgación de sus productos $y$ que, a la vez, sea un sitio para efectuar negociaciones y transacciones de exportación de café, así como para recibir información sobre disposiciones comerciales y de otra naturaleza relacionadas con la exportación de 
café. Específicamente, el "mercado virtual" propuesto ofrecerá un espacio para:

\section{Vendedores}

Todas aquellas personas, cooperativas o empresas productoras de café que accedan al portal con el propósito de promocionar y vender café y sus derivados, o con la intención de suscribirse a la base de datos de exportadores.

\section{Compradores}

Todas aquellas personas, empresas o entidades que accedan al portal con el propósito de comprar café, o para acceder a la información sobre empresas, certificaciones, contactos comerciales, así como aquellos con la intención de suscribirse a la base de datos de importadores o usar el sistema de subasta en reversa.

\section{Inversionistas}

Todas aquellas personas, empresas o entidades que accedan al portal con la idea de promocionar sus productos, como puede ser venta de maquinaria y equipo, fincas, tostadoras, beneficios, etc. A estos participantes, que podrían ser empresas extranjeras, el portal les ofrecería facilidades para dar a conocer y promover la venta de sus productos.

\section{Público en general}

Todas aquellas entidades o personas que accedan al portal para obtener información sobre las distintas oportunidades de negocios, compras y ventas de café.

\section{Actividades}

Las actividades involucradas en el diseño y la puesta en funcionamiento del portal serían las siguientes:

\section{Estructuración de Plan Estratégico de Negocios}

- Solución estratégica: contará con las respuestas operativas de la estructuración del mercado virtual; con este propósito, se contratarán los consultores necesarios para estructurar el modelo de negocios que haga viable la solución tecnológica que acompanará dicha propuesta. El modelo de negocios deberá incluir aspectos de la sostenibilidad financiera del portal, características técnicas del mismo, aspectos institucionales del portal, particularmente los de seguridad, así como las estrategias de mercadotecnia y desimanación.

- Solución tecnológica: es la respuesta operativa de la estructuración del mercado virtual; todas las actividades de esta solución estarán encaminadas a proveer la plataforma para la realización de ventas de café y otros productos vía internet. Con este propósito, se contratará a los consultores necesarios para estructurar el sitio web que permita contar con:

- Base de datos de exportadores clasificados por clase de café, denominación de origen, etc.: brindará información interactiva en un ambiente amigable y contendrá toda la información de contacto de los individuos exportadores, certificaciones, videos informativos, capacidades de producción, y estará ligada con un catálogo virtual con los productos que se ofrecen (por finca, variedades de café, ubicación geográfica de fincas, etc.), además de contar con herramientas para la transacción de muestras comerciales. Adicionalmente, acumulará un registro de experiencias (positivas, negativas o neutrales) y un campo para comentarios por usuario en aspectos de las transacciones con una calificación o rating, que será producido con base en la experiencia de los compradores en las transacciones que se generen. Además, se ofrecerán guías al importador potencial sobre cómo ordenar sus pedidos y cómo pagar por los mismos.

- Base de datos de importadores: contendrá información general del impor- 
tador, así como los productos que estos pretendan comprar. El importador y el comprador nacional manifestarán su interés en comprar determinadas variedades de café y las respectivas cantidades, y el rango de precios dispuesto a pagar, $\mathrm{y}$, así mismo, podrán solicitar el envío de muestras de características específicas. Adicionalmente, acumulará un registro de experiencias (positivas, negativas o neutrales) y un campo para comentarios por usuario, con una calificación o rating, que será producido con base en la experiencia de los compradores en las transacciones que se generen.

- Base de datos de productos: incluirá descripción y especificaciones de los productos, así como fotos y videos. Acumulará una bitácora con calificaciones o ratings en el sentido de calidad, volumen de ventas y popularidad, que será producido con base en las transacciones y la experiencia de los compradores.

- Sistema de subastas: ahí los exportadores podrán colocar sus productos bajo el sistema de subasta.

- Sistema de subastas en reversa: aquí los importadores podrán colocar sus demandas de café con la finalidad de que los exportadores hagan ofertas con el mejor precio posible $y$, así, se pueda observar en forma transparente las ofertas de sus competidores.

- Asistencia comercial en línea y por teléfono: servicio por el cual, personal especializado en comercio exterior, brinde soporte a importadores y exportadores sobre temas de comercio internacional (impuestos, regulaciones, transporte, servicios financieros, modalidades contractuales, etc.).

- Ferias virtuales: brindará un canal para la promoción de los productos y servicios a través de ferias electrónicas de café y sus derivados.

- Centro de servicios financieros: será espacio para proveedores de servicios financieros (cartas de crédito, créditos a la expor- tación, garantías, seguros, cambios de divisas, transferencias, etc.).

- Asesoría y asistencia técnica: será un centro especializado en brindar asistencia técnica a los exportadores relacionada con trámites de exportación, impuestos, transporte, idoneidad, aduanas, etc.

- Centro virtual de inversiones: contendrá toda la información y los contactos sobre inversión y oportunidades de inversión en $\mathrm{El}$ Salvador en áreas relacionadas con el café.

- Centro de información: contará con información y programas de capacitación sobre el comercio exterior y secciones informativas de cómo hacer negocios en El Salvador.

- Centro de emprendimiento: diseminará oportunidades de nuevos negocios, mediante la presentación de planes de negocios colocados en el portal por emprendedores, particularmente jóvenes, que serían puestos a la "venta" para motivar el interés de posibles inversionistas. Este sería como un eBay de proyectos.

\section{Sostenibilidad financiera}

Los recursos necesarios para desarrollar las actividades del portal en forma continua serán garantizados por medio de diversas fuentes:

- Venta de servicios de anuncios on line y off line dirigidos a importadores, exportadores, instituciones financieras, banca multilateral, agencias de cooperación y entidades del Estado, que serán desarrollados a través de las distintas fases del proyecto.

- Patrocinadores donantes que apoyan el portal y aporten recursos financieros.

- Desarrollo de investigaciones y proyectos en las áreas de desarrollo y acceso a mercados.

- Comisiones cobradas por transacciones realizadas. 


\section{Beneficios del Portal del Café de El Salvador}

Un portal, como el descrito anteriormente, constituirá un mecanismo rápido y eficaz para incrementar la información de ofertas y demandas del café salvadoreño. Esta posibilidad de contribuir a reducir y eliminar obstáculos e imperfecciones de mercado que las pequeñas empresas usualmente encuentran para exportar representará unos beneficios importantes en términos de disminuir los altos costos de mercado para lograr acceso a clientes potenciales y desarrollar negocios entre empresas (B2B). Esto sería un incentivo importante y conduciría que un mayor número de empresas, particularmente las pequeñas, participen activamente $-\mathrm{y}$ se beneficien- del mercado ampliado y de nuevas preferencias resultante del portal y de las oportunidades de mercados externos en general.

Un beneficio central sería facilitar el flujo de información conducente a llevar a cabo transacciones de compra y venta de café. Además, el portal contribuirá a la promoción de productos derivados del café, como licores, jabones, dulces, entre otros.

Además, la oportunidad que el portal presenta a las empresas para exportar, y el ser objeto de escrutinio por parte de importadores potenciales y de calificación por compradores actuales, sería un incentivo que conduciría a que las empresas cafetaleras salvadoreñas emprendieran esfuerzos para mejorar calidad y eficiencia, lo cual eventualmente serviría para que estén en mejores condiciones para exportar a otros países.

Asimismo, los productores de café serían beneficiados por el acceso a programas de tipo HelpDesk y ToolKitK, que encontrarían en el portal. Es decir, este sería una fuente de entrenamiento y conocimientos para el productor de café salvadoreño, al brindarle acceso a información sobre mejores prácticas de exportación y de calidad, así como sobre oportunidades de negocios, que de otra manera no estarían a su alcance.
También habría beneficios en el sentido de que el carácter precursor del portal constituiría un "laboratorio" para "experimentar" cómo hacer negocios por medio de internet, de manera que su éxito motivaría su réplica en otros productos de exportación. Es decir, el portal tendría la función de abrir brecha para posteriores aplicaciones con otros productos.

Un beneficio central se refiere igualmente a evitar que El Salvador se rezague en términos del nuevo tipo de intercambios de mercados que se realiza a través de e-commerce.

Un punto que se debe recalcar es que habría un proceso de selección de los productores que tendría acceso al uso del portal para vender sus productos, que dependería de la calidad del café, la existencia de marca, las existencias actuales, etc. Un ente nacional, como el Consejo Salvadoreño del Café, por ejemplo, conjuntamente con otras dependencias, apoyarían a los productores para que sean elegibles de usar el portal, y los apoyaría también en las tareas de trámites de exportación.

Finalmente, hay que señalar que permitir que un monto mayor de caficultores pequeños participen en el portal sería un medio para apoyar los segmentos de menores ingresos de la población, lo cual contribuiría a generar un ambiente propicio para la recuperación de la caficultura.

Todos los desarrollos tecnológicos del portal serán puestos a disposición del resto de América Latina y del Caribe. 